\title{
Call for Papers: 1988 MRS Spring Meeting
}

The 1988 Spring Meeting of the Materials Research Society will be held April 5-9 at the Bally Grand Hotel in Reno, Nevada. This year's meeting will feature 15 technical symposia, a shorl course program of approximately 22 courses, an equipment exhibit, and a job placement center. MRS extends a broad invitation to materials scientists and engineers to participate in all aspects of the meeting.

The symposia will share a common goal of discussing new materials developments, new characterization methods, or new process technology. Each symposium will provide a forum for exchanging ideas at the forefront of research with experts in the field. Topics will be treated at a sophisticated level, in an interdisciplinary way, so all possible physical, chemical, and engineering insights can be considered.

Papers which will contribute to the state of knowledge in a given area are solicited for all symposium topics. The topics for each symposium are described below. For additional information on a specific symposium, contact the symposium organizers listed at the end of the description for each symposium.

Abstracts are to be prepared in the new MRS abstract format and submitted to the organizers of the individual symposia. Except for Symposium $\mathrm{K}$, the deadline for $\mathrm{ab}$ stracts to be in the hands of the symposium organizers is October 1, 1987. The deadline for Symposium K only is January 10, 1988.

For general information on the technical program, contact any of the Program Chairs:

David E. Clark

Department of Materials Science

\& Engineering

University of Florida

Gainesville, FL 32611

(904) $392-7660$

\section{Clif Draper}

AT\&T Engineering Research

P.O. Box 900

Princeton, NJ 08540

(609) 639-2350

C.T. Liu

Oak Ridge National Laboratory

P.O. Box X

Oak Ridge, TN 37831

(615) $574-4459$

\section{Symposium A}

\section{Heteroepitaxy on Silicon:}

Fundamentals, Structures, and Devices

This symposium will expand the scope of previous MRS symposia on heteroepitaxial growth on silicon by addressing fundamental phenomena of epitaxial growth and investigating specific materials and device systems. Particular emphasis will be placed on: emerging new heteroepitaxial combinations; progress of $\mathrm{GaAs} / \mathrm{Si}$, GeSi/Si and epi- taxial fluorides and silicides; developments in fundamental understanding, materials growth, and characterization; and emerging device applications such as monolithic III-V/ $\mathrm{Si}$ integration, and high temperature wide bandgap semiconductor technologies. Contributions are solicited in the following and related fields:

- Fundamentals of heteroepitaxial growth on $\mathrm{Si}$

- Growth and characterization of heteroepitaxial layers on Si III-V and II-VI compounds on $\mathrm{Si}$

- Group IV heteroepitaxy (GeSi/Si, SiSn/Si and high temperature wide bandgap semiconductors such as $\mathrm{SiC} / \mathrm{Si}$ )

- Epitaxial metals and insulators on Si

- Novel devices in heteroepitaxial structures on $\mathrm{Si}$

- Monolithic GaAs/Si integration

Send abstracts to R.J. Nemanich at the address below.

Symposium Organizers:

Hong K. Choi

Lincoln Laboratory

Massachusetts Institute of Technology

244 Wood Street

Lexington, MA 02173

(617) 863-5500, Ext. 4457

Robert Hull

AT\&T Bell Laboratories

600 Mountain Avenue

Murray Hill, NJ 07974

(201) $582-3000$

Hiroshi Ishiwara

Tokyo Institute of Technology

4259 Nagatsuda

Yokohama 227, Japan

011-81-45-922-1111, Ext. 2552

Robert J. Nemanich

Department of Physics

North Carolina State University

Raleigh, NC 27695-8202

(919) 737-3225

\section{Symposium B \\ Materials for}

Controlled-Release Environments

This symposium will highlight recent developments in materials for controlledrelease application. It will be interdisciplinary, emphasizing scientific and engineering developments in polymer science, ceramics, and metals that are important in the design of controlled-release systems in pharmaceutics, agriculture, and environmental science. Areas of interest include transdermal and implantable drug delivery systems, pesticide and animal health care products, environmental reclamation, sensors, diagnostics, and lithography. Contributions are solicited in the following areas:

- Diffusion in polymers

- Biodegradable/bio-erodible polymers
- Swelling of polymers in biological fluids

- Transdermals

- Ceramic and metal-based controlled release

- Bioadhesion and biological surface interactions with materials

- Biosensors

- Materials effects on protein stability

Symposium Organizers:

Kristine Knutson

Department of Pharmaceutics

University of Utah

Salt Lake City, UT 84112

(801) 581-4426

Robert Langer

Room 342, Whitaker Health Science Building Massachusetts Institute of Technology

Cambridge, MA 02139

(617) 253-3107

Ronald A. Siegel

School of Pharmacy, 926-S

University of California

San Francisco, CA 94143

(415) 476-5194

\section{Symposium C \\ Process Dlagnostics}

Materials and process development is often done using the Edisonian approach of varying one process parameter at a time and observing changes in some desired material property. As processes (e.g. microelectronic fabrication) increase dramatically in their complexity, the validity of this method is called into question, particularly in light of new diagnostic techniques which provide a microscopic view of atomic and molecular interactions. This symposium is designed to bring together scientists and engineers who are attempting to obtain a fundamental understanding of processes occurring in the gas phase and at gas/solid and gas/liquid interfaces. Its goal is to create a dialogue between scientists and engineers who are already using sophisticated diagnostic techniques to study combustion and magnetic confinement fusion processes and material scientists who wish to increase their understanding of how process parameters affect microelectronic fabrication, coating technologies, and ceramic and metallurgical processing.

Contributions are solicited in the following areas:

- Process diagnostics for microelectronics fabrication (PVD, CVD, PECVD, plasma etching...)

- Process diagnostics for industrial coating technologies (plasma spraying, PVD, CVD, PECVD...)

- Diagnostics for ceramic and metallurgical processing (powder synthesis, welding, melting, refining, surface modification...)

- Combustion diagnostics (internal combus- 
tion engines, rocket engines, explosive detonations...)

- Magnetic confinement fusion diagnostics (plasma-surface interactions, edge diagnostics...)

Symposium Organizers:

Kay Hays

Division 1831

Sandia National Laboratories

Albuquerque, NM 87185

(505) 844-9996

Alan Eckbreth

United Technologies Research Center

Silver Lane

E. Hartford, CT 06108

(203) $727-7269$

Greg Campbell

Center for Plasma Physics \& Fusion

Engineering

University of California

Los Angeles, CA 90024

(213) $825-3419$ or (818) 841-4094

\section{Symposium D \\ Diamond and Diamond-Like Materials Synthesis}

Over the past 30 years, researchers have synthesized single-phase diamond films using thermal-, catalyst-, photon (UV)-, and electron-assisted CVD; rf- and microwaveplasma-assisted CVD and sputtering techniques. Polycrystalline and continuous single phase diamond films, as well as diamond crystals, have been deposited using a variety of hydrocarbon gases.

This symposium will focus on these films' physical and chemical properties, as well as their performance properties in potential applications. These properties will be discussed as a function of the deposition techniques and their parameters. The roles of plasma chemistry, nonequilibrium kinetics, and film morphology and characterization will also be addressed.

Speakers should submit five copies of their abstracts.

Symposium Organizers:

George $\mathrm{H}$. Johnson

Electronic Specialties Laboratory

Philips and Du Pont Optical Company

E.I. du Pont de Nemours \& Company

Chestnut Run Bldg. 709 Laboratory 7

Wilmington, DE 19898

(302) 999-4814

Michael Geis

Lincoln Laboratory

Massachusetts Institute of Technology

P.O. Box 73

Lexington, MA 02173-0073

(617) 863-5500, Ext. 4658

Andrzej Badzian

Materials Research Laboratory

Pennsylvania State University

University Park, PA 16802

(814) 863-1967

\section{Symposium E}

Amorphous Silicon Technology

This symposium will be devoted to materials issues related to applications to amorphous semiconductors, including amorphous silicon-based alloys. Specific issues will include structure, electronic and optical properties, defects, interfaces, contacts, heterostructures, nonequilibrium behavior, and stability. Applications will include solar cells, electro-photography, switching, electronic and optical memories, image sensors, scanners, thin-film transistors, vidicons, large-area displays, portable computers, and new types of devices. Presentations will focus on the electronic density of states and its relationship to technological figures of merit for each application, fundamental and materials limitations, yield, reproducibility, reliability, and stability.

Papers are solicited, but not limited to the following areas: structure, optical properties, electronic properties, defects, contacts, interfaces, heterostructures, nonequilibrium properties, solar cells, electrophotography, switching, electronic memories, optical memories, computers, large-area displays, vidicons, image sensors, scanners, novel devices, stability, transient behavior, alloys.

Send abstracts to A. Madan at the address below.

\section{Symposium Organizers:}

Y. Hamakawa

Osaka University

1-1 Machikaneyma

Toyonaka, Osaka 560

Japan

P.G. LeComber

University of Dundee

Carnegie Laboratory of Physics

Dundee DD1 4HN UK

44-382-23181

A. Madan

Glasstech Solar, Inc

12441 West 49 th Avenue

Wheatridge, CO 80033

(303) 425-6600

P.C. Taylor

University of Utah

Department of Physics

Salt Lake City, UT 84112

(801) 581-4484

M.J. Thompson

Xerox PARC

3333 Coyote Hill Road

Palo Alto, CA 94304

(415) 494-4561

\section{Symposium F}

\section{Adhesion in Solids}

Adhesion of surfaces in contact is of interest to those seeking a fundamental understanding of metals, polymers, superconductors, semiconductors, and ceramics and their applications. This symposium will bring together scientists and engineers to promote the dissemination of ideas, theories, and facts relating to adhesion, adhesion failure, and adhesion promoting or preventing processes. General areas of interest include: interface structure and characterization; mechanics and fracture of interfaces; degradation of adhesion (e.g. corrosion, diffusion); thin film formation-nucleation, interface formation, film properties; modification of surfaces and interfaces to promote or prevent adhesion; techniques for measuring and evaluating adhesion.

Contributions are solicited in such areas as:

- Adhesion or corrosion layers

- Ion beam processing

- Device contacts

- Real-time fracture analysis

- Plasma treatment of polymer surfaces

- Device packaging

- Friction of ceramic surfaces

- Degradation of metal-polymer interfaces

- Coating adhesion in mechanical applications

- Sintering of powders

- Environmental effects on wear

- Adsorption and nucleation of surfaces

- Diffusion at interfaces

- Bioadhesion

- Fine particle adhesion

Symposium Organizers:

D.M. Mattox

1834 Surface and Interface Technology

Sandia National Laboratories

Albuquerque, NM 87185

(505) 844-7632

Chris Batich

Materials Science \& Engineering Dept.

University of Florida

Gainesville, FL 32611

(904) 392-6630

J.E.E. Baglin

IBM Almaden Research Center

K34/802

650 Harry Road

San Jose, CA 94120-6099

R.J. Gottschall

ER 131:MS G236/GTN

Division of Materials Sciences USDOE Washington, DC 20545

(301) $353-3428$

\section{Symposium G \\ High Temperature/High Performance Composites}

This symposium will bring together researchers from widely dispersed fields to compare their latest results concerning the synthesis, structure-property relationships, and mechanics of metal, intermetallic, glass, and ceramic matrix composites. Both artificial and in situ reinforced composites (produced by co-deformation, controlledeutectic solidification, and reactively formed 
reinforcements) will be addressed. The reinforcement formats comprise continuous filaments, whiskers, and particulates.

Contributions are solicited in the topical areas described above. Emphasis will be placed on new methods of preparation and characterization, new material systems, composition-property relationships, and process effects on properties.

Submit abstracts to F.D. Lemkey at the address below.

Symposium Organizers:

F.D. Lemkey

United Technologies Research Center, MS 25

E. Hartford, CT 06108

(203) 7277318

A.G. Evans

Eng. II, Rm. 1355

University of California

Santa Barbara, CA 93106

(805) 961-3141

S.G. Fishman

Office of Naval Residence

800 N. Quincy Street

Arlington, VA 22217

(202) 696-4401

J.R. Strife

United Technologies Research Center, MS 24

E. Hartford, CT 06108

(203) 7277270

\section{Symposium H}

Better Ceramics Through Chemistry III

This symposium will address the synthesis, structure and new applications of chemically derived ceramic materials. The first sessions will address the chemistry and structure of ceramic precursors. Subsequent sessions will address forming these substances into gels, films, powders, or fibers, and conversion to glasses, ceramics, or composites. Recent results on films and coatings will also be emphasized. A session on chemical processing of high temperature superconductors has been tentatively planned. Contributions are solicited in the following areas:

- Synthesis and chemistry of ceramic precursors

- Chemical routes to gels, powders, films or fibers

- Structure and structure-property relationships

- Advances in materials characterization

- Films and coatings: synthesis, structure and applications

- Theoretical modeling: MO/MD calculations, computer simulations

- Joining: sealing and repair

- Processing of high temperature superconductors

Submit two copies of the abstract to $C$. Jeffrey Brinker at the address below.

Symposium Organizers:

C. Jeffrey Brinker

Div. 1846
Sandia National Laboratories

Albuquerque, NM 87185

(505) 846-3552

D.E. Clark

Dept. of Materials Science \& Engineering

University of Florida

Gainesville, FL 32611

(904) 3927660

Don R. Ulrich

Air Force Office of Scientific Research

Bolling Air Force Base

Washington, DC 20332

(202) $767-4963$

\section{Symposium J \\ Science and Technology of Refractory Alloys}

Interest in refractory metals for advanced engineering systems and electronic applications has grown substantially in the last few years. To date, this interest has expanded without the benefit of timely symposia on these applications and the new base of applied and fundamental knowledge that has been generated over the past decade. This symposium will focus on new applications and determine the state of knowledge. Contributions are solicited in the following areas: - Current and anticipated applications, such as electronics and aerospace (e.g., propulsion, reentry), space power, fusion and other radiation environments, VLSI metallization, specialized applications (e.g., capacitors, filaments, heating elements, electrodes, $x$-ray targets)

- Applied technology considerations, such as: processing (e.g., joining, forming, machining, melting, PM), coatings (e.g., PVD, CVD, sputtering, slurry fusion, diffusion barriers), environmental reactions and compatibility (e.g., oxidation, atomic oxygen, hydrogen, inert gases, high vacuum, alkali metals, propulsion gases, liquid and solid propellants)

- Fundamental topics, such as: alloy design, diffusion, microstructural control, deformation and fracture mechanisms, gas-metal interactions, phase equilibrium, reaction kinetics (e.g., silicide formation), thermal, electrical, electronic and optical properties, solidification phenomena

Symposium Organizers:

Roy H. Cooper, Jr.

Oak Ridge National Laboratory

P.O. Box X

Oak Ridge, TN 37831-6153

(615) 574-4470

Ronald Gibala

Dept. of Materials Science \& Engineering

University of Michigan

Ann Arbor, MI 48109-2136

(313) 763-4970

Charles M. Packer

Lockheed Palo Alto Research Center

3251 Hanover Street

Palo Alto, CA 94304-1187
(415) 424-2267

Jeffrey Wadsworth

Lockheed Palo Alto Research Center

3251 Hanover Street

Palo Alto, CA 94304-1191

(415) 424-2234

\section{Symposium K}

High Temperature Superconductors

This symposium will provide a multidisciplinary forum focused on the exciting new developments in high temperature superconductivity. Contributions are solicited in the following areas:

- Superconducting properties $\left(T_{c}, H_{c 2}, J_{c}\right.$ etc.)

- Electron-electron coupling mechanisms and prospects for higher TCS

- Materials properties and microstructure

- Processing, fabrication and characterization

- Current and future applications

Contributing speakers should submit five copies of abstracts to D. Capone by January 10, 1988.

Symposium Organizers:

Bertram Batlogg

AT\&T Bell Laboratories

Room 1D237

600 Mountain Avenue

Murray Hill, NJ 07974-2070

(201) 582-6663

W.H. Butler

Oak Ridge National Laboratory

Building 4500S, MS-114

P.O. Box X

Oak Ridge, TN 37831-6114

(615) 574-4845

Don Capone

Argonne National Laboratories

Building 223, Room A113

9700 South Cass Avenue

Argonne, IL 60439

(312) $972-5526$

Paul C.W. Chu

Department of Physics

University of Houston

Houston, TX 77004

(713) $749-2842$

Symposium L
Materials Issues in
Art and Archaeology
Cosponsored by the Getty Conservation In-
stitute and Conservation Analytical Labora-
tory, Smithsonian Institution

The methods and analytical techniques of materials science have been central to advances in art history, archaeology and conservation. Recent developments in materials research have been applied to problems such as authenticity, preservation, dating, provenance, raw materials sourcing, and understanding the diversity and complexity of ancient technologies. In addition, there is a growing body of research data on ancient

Continued 
technology which has developed within the field of archaeometry on systems which should be of interest to university or industrial materials researchers.

Contributions are solicited in the following areas:

- Technical methods of examining and characterizing artifacts and works of art (e.g., materials characterization and methods of analysis in art and archaeology, in particular nondestructive and microsampling techniques)

- Technical studies of the technologies of ancient and historic manmade materials (e.g., metals, ceramics and polymers), including investigation of properties, reconstruction of processing, characterization of macro- and microstructure, role of technology in social evolution, interaction of technologies, processes of technological innovation and development

- Deterioration of natural, ancient and modern glasses: models, mechanisms and treatment

Submit three copies of camera-ready abstracts.

\section{Symposium Organizers:}

Edward V. Sayre and Pamela Vandiver Conservation Analytical Laboratory

Smithsonian Institution

Washington, DC 20560

(202) 287-3700

James Druzik

Getty Conservation Institute

4503 Glencoe Avenue

Marina Del Rey, CA 90292

(213) 822-2299

Christopher Stevenson

Archaeological \& Historical

Consultants, Inc

P.O. Box 182

Boalsburg, PA 16827

(814) 466-7549

\section{Symposium M \\ Microwave Processing of Materials}

Endorsed by the American Ceramic Society

This is the first major international symposium on the use of microwave energy applied to materials processing, including industrial applications. Speakers will highlight progress and recent developments in the microwave processing of materials and products from research, development, and production viewpoints. Contributions are solicited in such areas as:

- Fundamentals of microwaves/materials interactions and modeling; microwavemicrostructure-property relationships

- Application of M/W to inorganic materials, including ceramics, glasses, glass-ceramics, non-oxides, composites, minerals

- Application of $\mathrm{M} / \mathrm{W}$ to organic materials, including: polymers, adhesives, rubber, textiles, forest products, and food

- Application of $M / W$ to medical and biological systems
- Examples of technological applications of the above, including reclamation and pollution control

Symposium Organizers:

Merton H. Brooks

Sandia National Laboratories

Division 7472

Albuquerque, NM 87115

(505) 844-6800

Irving J. Chabinsky

I.J.C. Technologies, Inc.

8 Paul Revere Rd.

Acton, MA 01720

(617) 263-7911

Willard H. Sutton

United Technologies Research Center

MS-24, Silver Lane

East Hartford, CT 06108

(203) $727-7639$

\section{Symposium $\mathbf{N}$ Materials Stability} and Environmental Degradation

This symposium will focus on scientific advances in understanding the mechanisms of corrosion and degradation of such materials as metals, glass and ceramics, polymers, and composites. Topics of interest include the dependence of rates and mechanisms of environmental degradation on materials composition and fabrication as well as on environmental conditions.

Contributions are solicited in the general area of mechanisms of degradation, dissolution, stress corrosion, and oxidation, as well as the development of materials of high stability in specific environments, including:

- Ceramics and alloys for high temperature applications

- Homogenous and composite structural materials

- Optical components and fibers based on oxide and non-oxide glasses

- Radiation-resistant alloys and ceramics

- Materials with high biological stability for environmental and biomedical applications

- Natural, ancient and modern glasses, ceramics, and metals

Symposium Organizers:

L.R. Smith

Polymer Division, Rm. A305

National Bureau of Standards

Gaithersburg, MD 20899

(301) 975-6762

E. Verink

706 Clopper Rd., Apt. 22

Gaithersburg, MD 20878

(301) 975-6027

A. Barkatt

Vitreous State Laboratory

Catholic University of America

Washington, DC 20064

(202) 635-5522

\section{Symposium $\mathbf{P}$ \\ Advanced Surface Processes \\ for Optoelectronics}

Major advances in preparing and processing material surfaces could significantly influence the future of optoelectronics. This symposium will bring together researchers from a variety of disciplines who are involved in the various aspects of modifying and preparing surfaces with desired electronic and optical properties. Contributions are solicited in the following areas:

- Focused ion beams for direct doping, etching and deposition

- Enhancement of intermixing of superlattice layers by introduction of dopants

- Ion-implanted waveguides in insulators and semiconductors

- Beam-induced etching of optoelectronic structures

- Beam-enhanced epitaxial growth

- Ion implantation and RTA in III-V materials

- Optoelectronics on silicon (oxides, nitrides, epi-insulators and compound semiconductors)

- Strained layer superlattices

- Novel ohmic contacts to III-V materials

- Passivation layers for devices

- Fabrication of ultrasmall structures

- In situ processing

Symposium Organizers:

T. Venkatesan

Bellcore

Red Bank, NJ 07701

(201) 758-3254 or (201) 699-2223

S. Bernasek

Department of Chemistry

Princeton University

Princeton, NJ 08544

(609) 452-4986

G. Stillman

Dept. of EE \& Computer Engineering

University of Illinois

1406 W. Green Street

Urbana, IL 61801

(217) 333-3097

H. Temkin

Rm. 7A-213

AT\&T Bell Laboratories

Murray Hill, NJ 07974

(201) 582-3185

1988 MRS Spring Meeting

April 5-9

Reno, Nevada 


\section{SHORT COURSE PROGRAM}

\section{MRS Fall Meeting}

\section{November 30-December 5 Boston, Massachusetts}

A roster of 29 short courses on advanced materials research techniques will complement the technical program at the 1987 MRS Fall Meeting. The courses have been scheduled to give short course attendees time to participate in symposia with parallel topics. Individuals registered for two or more short course days may attend the 1987 MRS Fall meeting at the special fee of $\$ 50$.

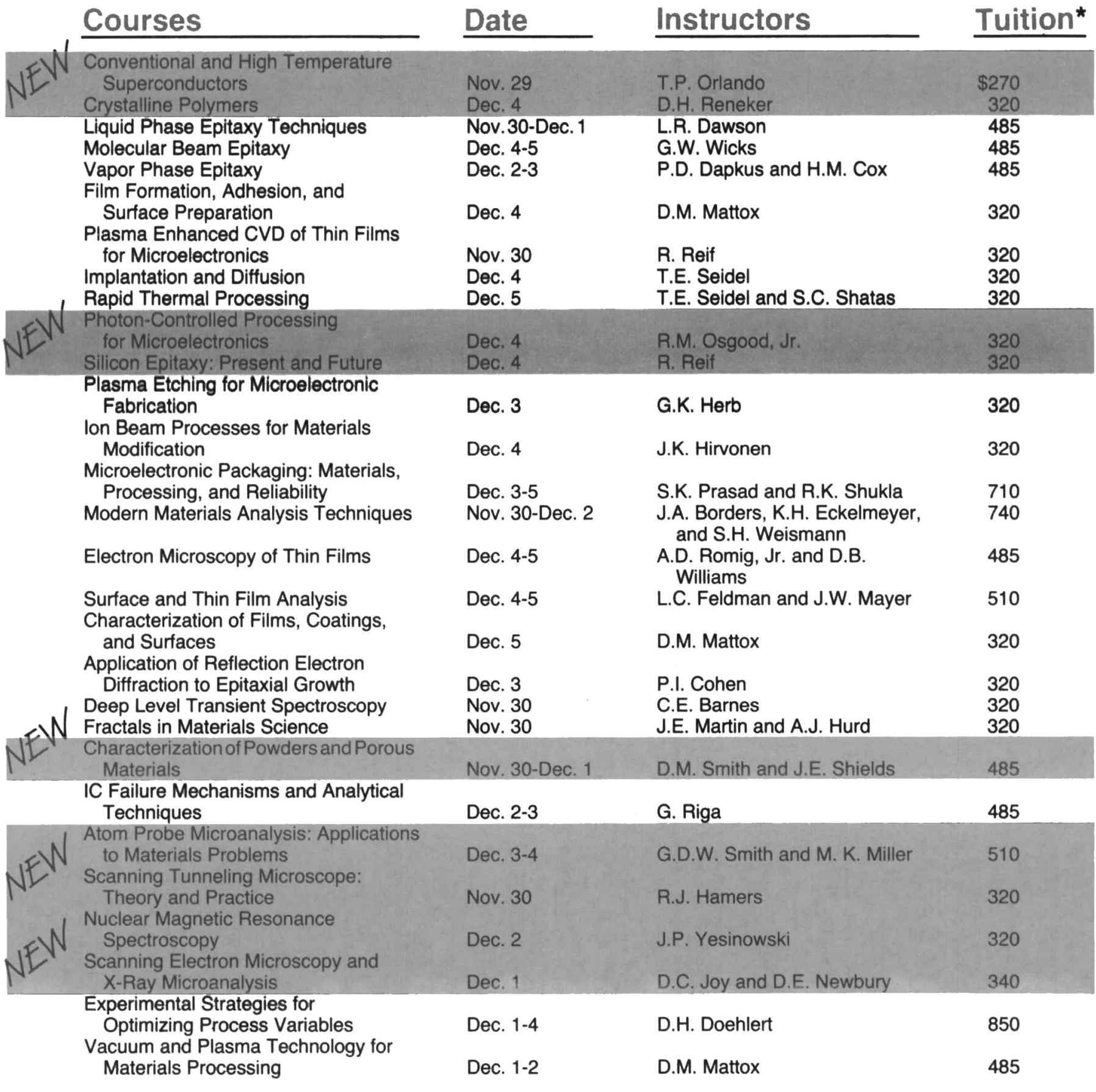

*Tuition discounts are available to registrants attending certain groups of courses and to students. All registrations made after November 16, 1987 will be $\$ 25$ higher for each course. For further details or to register, contact: 